\title{
Perancangan Turbin Angin Jenis Helical untuk Sistem Pembangkit Listrik
}

\author{
Nur Rahmah H. Anwar ${ }^{*}$ \\ ${ }^{1}$ Jurusan Teknik Mesin, Politeknik Negeri Ujung Pandang, Makassar 90245, Indonesia \\ *nurrahmah@poliupg.ac.id
}

\begin{abstract}
This research aims to meet the demand for electricity on the road and to reduce dependence on fossil fuels. The process of designing a helical type power plant system is carried out by identifying needs technical specifications, conceptual design, design selection and power calculation analysis and wind turbine rotation simulation analysis. The electrical energy generated by this helical turbine is stored in dry batteries to be used as a source of electricity for street light lighting. The results of the design selection obtained a helical type turbine design with a blade height of $1.000 \mathrm{~mm}$, and blade widht of $151 \mathrm{~mm}$. The rotor diameter is $750 \mathrm{~mm}$. The results of the analysis of the power generated by two turbine units are 3.319,69 Wh. Electrical energy stored in a $24 \mathrm{~V} d r y$ battery with a capacity of energy for street light lighting for 12 hours for 2 LED lamps $55 \mathrm{~W} 24$ Volt DC with a total usage load of $1.518 \mathrm{Wh}$. This turbine can be used in certain areas where many vehicles pass.
\end{abstract}

Keywords: helical wind turbine; electrical energy; street light

\begin{abstract}
Abstrak: Penelitian ini bertujuan untuk memenuhi kebutuhan listrik di jalan raya dan untuk mengurangi ketergantungan terhadap bahan bakar fosil. Proses perancangan sistem pembangkit listrik jenis helical dilakukan dengan mengidentifikasi kebutuhan, spesifikasi teknis, perancangan konsep, seleksi desain dan analisis perhitungan daya serta analisis simulasi putaran turbin angin. Energi listrik yang dihasilkan oleh turbin helical ini disimpan ke dalam aki kering untuk dimanfaatkan sebagai sumber listrik penerangan lampu jalan. Hasil seleksi desain diperoleh rancangan turbin angin jenis helical dengan tinggi sudu $1.000 \mathrm{~mm}$, lebar sudu $151 \mathrm{~mm}$. diameter rotor $750 \mathrm{~mm}$. Hasil analisis daya yang dihasilkan oleh dua unit turbin sebesar 3.319,69 Wh. Energi listrik yang tersimpan di dalam aki kering $24 \mathrm{~V}$ kapasitas 70 Ah sebagai sumber energi penerangan lampu jalan selama 12 jam untuk 2 buah lampu LED 55 W 24 Volt DC dengan total beban pemakaian sebesar $1.518 \mathrm{Wh}$. Turbin ini dapat digunakan pada wilayah tertentu yang dilalui oleh banyak kendaraan.
\end{abstract}

Kata kunci : turbin angin helical; energi listrik; lampu jalan

\section{PENDAHULUAN}

Kebutuhan energi listrik di Indonesia pada umumnya terus meningkat sedangkan saat ini kita dihadapkan pada masalah ancaman kelangkaan energi fosil yang ketersediaannya di alam sangat terbatas dan banyak mencemari lingkungan. Sebagaimana yang diketahui bahwa kebutuhan listrik akan terus meningkat dan PLN saat ini tidak lagi menyuplai listrik ke jalan raya akibat tingginya beban biaya yang harus di tanggung oleh PLN. Hal ini menyadarkan kita untuk segera mengembangkan dan menerapkan sumber energi terbarukan guna mengurangi ketergantungan terhadap bahan bakar fosil. Energi angin merupakan salah satu energi terbarukan yang dinilai efisien dalam penggunaannya. Berbagai macam penemuan turbin angin sebagai pembangkit energi alternatif sudah ditemukan sejak lama dengan berbagai macam bentuk desain. Turbin angin helical adalah salah satu jenis turbin angin vertikal yang mampu menangkap angin dari berbagai arah dan beroperasi pada kecepatan angin rendah. Dengan memperhatikan hal tersebut, maka muncul sebuah gagasan untuk memanfaatkan hembusan kendaraan yang memiliki potensi sebagai sumber energi untuk memenuhi kebutuhan listrik penerangan jalan umum.

Salah satu ciri dari aktivitas perancangan adalah bahwa selalu dimulai dari awal dan berakhir di awal. Artinya fokus dari semua aktifitas perancangan adalah titik akhir (deskripsi produk). Proses pembuatan tidak akan berjalan dengan baik sebelum kegiatan perancangan diselesaikan. 
Quality Function Deployment (QFD) adalah sebuah sistem pengembangan produk yang dimulai dari merancang produk, proses manufaktur sampai produk tersebut ke tangan konsumen, dimana pengembangan produk berdasarkan pada keinginan konsumen [1].

Ada beberapa tahap yang dilakukan pada proses perancangan ini, yakni:

1. Identifikasi kebutuhan

2. House of quality (HOQ)

3. Perancangan konsep desain meliputi black box, struktur fungsi, morphological chart.

4. Seleksi desain meliputi pohon keputusan dan konsep penilaian

Energi angin merupakan sumber daya alam yang terbarukan dan memiliki jumlah yang tidak terbatas di sekitar permukaan bumi. Turbin angin merupakan salah satu alat yang mekanisme geraknya memanfaatkan energi angin. Besarnya daya mekanik dari rotor dapat dihitung dengan menggunakan persamaan: [2]

$$
P_{m}=T\left(\frac{2 \pi n}{60}\right)
$$

Daya angin adalah daya yang dibangkitkan oleh angin tiap luasan, sehingga daya angin dapat digolongkan sebagai energi potensial. Pada dasarnya daya angin yang bergerak persatuan waktu sehingga dapat dirumuskan sebagai berikut:

$$
P_{a}=1 / 2 \cdot \rho \cdot A \cdot V^{3}
$$

Daya turbin angin adalah daya yang dibangkitkan oleh rotor turbin akibat mendapatkan daya dari hembusan angin. Daya turbin angin tidak sama dengan daya angin dikarenakan daya turbin angin terpengaruh oleh koefisien daya.

$$
P_{t}=C_{p} \cdot 1 / 2 \cdot \rho \cdot A \cdot V^{3}
$$

Efisiensi turbin angin dapat dihitung dengan menggunakan persamaan:

$$
\eta=\frac{C_{P} \cdot 1 / 2 \cdot \rho \cdot A \cdot V^{g}}{1 / 2 \cdot \rho \cdot A \cdot V^{g}} x 100 \%
$$

Profil airfoil adalah elemen paling penting dalam konversi energi angina yang memberikan nilai koefisien drag yang kecil jika dibandingkan dengan lift yang diberikan. Profil airfoil yang digunakan adalah Profil NACA 4412 [3].

Secara matematis, hubungan gaya drag dan lift dengan koefisiennya dapat dirumuskan sebagai berikut: [4]

$$
\begin{aligned}
& F_{D}=\frac{1}{2} C_{D} \rho V^{2} A \\
& F_{L}=\frac{1}{2} C_{L} \rho V^{2} A
\end{aligned}
$$

Gaya-gaya yang terjadi pada rotor adalah gaya tangensial dan gaya aksial yang diperoleh dengan persamaan:

$$
\begin{aligned}
& F_{t}=F_{L} \cos \varphi+F_{D} \sin \varphi \\
& F_{a}=F_{L} \sin \varphi-F_{D} \cos \varphi
\end{aligned}
$$

\section{METODE PENELITIAN}

Penelitian dilakukan dengan merancang dan merencanakan turbin angin helical [5] sebagai sumber pembangkit listrik untuk penerangan jalan dengan memanfaatkan hembusan kendaraan. Pengumpulan data dilakukan dengan mengumpulkan informasi tambahan mengenai arah angin, kecepatan angin dan frekuensi kendaraan secara aktual. Setelah diperoleh data-data dari hasil studi literatur dan data dari alat yang dirancang, maka selanjutnya dilakukan analisis perhitungan daya yang 
dihasilkan dan simulasi putaran pada turbin dengan menggunakan CFD (Computational Fluid Dynamics.)

\section{HASIL DAN PEMBAHASAN}

Setelah daftar kebutuhan terpenuhi seperti yang ditunjukkan pada tabel 1, selanjutnya dilakukan perancangan konsep desain dan seleksi desain varian turbin.

Tabel 1

Daftar Kebutuhan

\begin{tabular}{|c|l|c|}
\hline No & \multicolumn{1}{|c|}{ Daftar Kebutuhan } & Tingkat Kepentingan \\
\hline 1 & Listrik yang dihasilkan optimal & 5 \\
\hline 2 & Daya besar & 5 \\
\hline 3 & Pergantian komponen mudah & 4 \\
\hline 4 & Mudah di produksi & 3 \\
\hline 5 & Mudah di rawat & 3 \\
\hline 6 & Tahan lama & 4 \\
\hline 7 & Ergonomis & 5 \\
\hline 8 & Stabil digunakan & 4 \\
\hline 9 & Kapasitas listrik bertahan lama & 5 \\
\hline
\end{tabular}

Desain varian pada gambar 1 adalah hasil seleksi varian terbaik dan dipilih sebagai konsep perancangan turbin angin jenis helical untuk sistem pembangkit listrik.

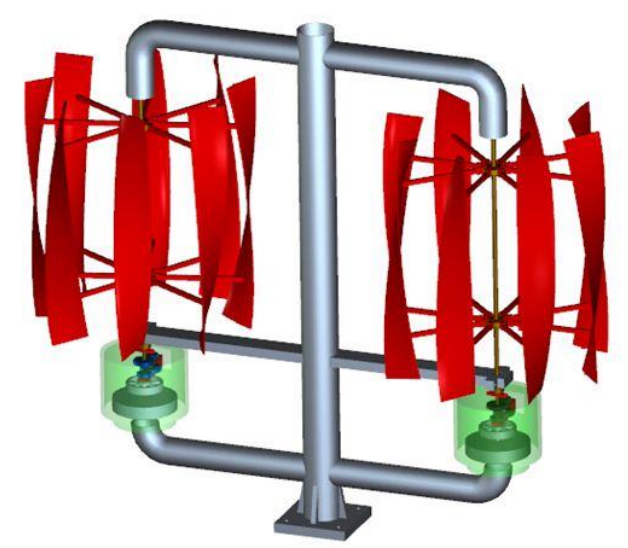

Gambar 1. Turbin angin jenis helical untuk sistem pembangkit listrik

Berdasarkan hasil eksperimental yang telah dilakukan dengan pengambilan data kecepatan angin, frekuensi kendaraan dan arah angin, maka dihasilkan data perancanaan untuk desain sebuah turbin helical seperti yang ditunjukkan pada tabel 2 .

Tabel 2. Data perencanaan turbin helical

\begin{tabular}{|c|c|c|c|c|}
\hline $\begin{array}{c}\text { Diameter Poros } \\
(\mathbf{m m})\end{array}$ & $\begin{array}{c}\text { Tinggi } \\
\text { Sudu (mm) }\end{array}$ & $\begin{array}{c}\text { Diameter } \\
\text { Rotor (mm) }\end{array}$ & $\begin{array}{c}\text { Jari - Jari } \\
\text { Rotor (mm) }\end{array}$ & $\begin{array}{c}\text { Jumlah Sudu } \\
(\text { buah) }\end{array}$ \\
\hline 20 & 1000 & 750 & 375 & 8 \\
\hline
\end{tabular}


Besarnya pemanfaatan angin dari hembusan kendaraan yang berpotensi sebagai sumber energi untuk menggerakkan turbin tergantung pada jumlah kendaraan yang melintasi wilayah tersebut. Sehingga banyaknya kendaraan yang melintas setiap 60 menit merupakan fungsi dari frekuensi mobil.

$$
f=\text { jumlah kendaraan } / 60 \text { menit }
$$

Kondisi 1: $\quad f=\frac{709}{60}=11,817 \mathrm{~Hz}$

Kondisi 2: $\quad f=\frac{1187}{60}=19,783 \mathrm{~Hz}$

Kondisi 3: $\quad f=\frac{1133}{60}=18,833 \mathrm{~Hz}$

Kondisi 4: $\quad f=\frac{948}{60}=15,8 \mathrm{~Hz}$

Dengan demikian, maka putaran pada poros turbin akan didapatkan dengan menggunakan persamaan

$$
\mathrm{n}=2 \pi f
$$

sehingga di dapatkan,

Kondisi $1=74,276$ RPM

Kondisi $2=124,352$ RPM

Kondisi $3=118,695$ RPM

Kondisi $4 \quad=99,314$ RPM

\section{Tip speed ratio $(\lambda)$}

Tip speed ratio (rasio kecepatan ujung) merupakan hasil perbandingan kecepatan dari ujung sudu turbin yang berputar terhadap kecepatan angin [6]. Dengan menggunakan persamaan, maka diperoleh:

Kondisi 1: $\quad \lambda=\frac{\pi x 0,75 \mathrm{~m} x 74,276 \mathrm{RPM}}{60 \times 2,2 \mathrm{~m} / \mathrm{s}}=1,326$

Kondisi 2: $\quad \lambda=\frac{\pi x 0,75 \mathrm{~m} x 124,352 \mathrm{RPM}}{60 \times 2,2 \mathrm{~m} / \mathrm{s}}=2,221$

Kondisi 3: $\quad \lambda=\frac{\pi x 0,75 \mathrm{~m} x 118,695 \mathrm{RPM}}{60 \times 2,2 \mathrm{~m} / \mathrm{s}}=2,120$

Kondisi 4: $\quad \lambda=\frac{\pi x 0,75 \mathrm{~m} x 99,314 \mathrm{RPM}}{60 \times 2,2 \mathrm{~m} / \mathrm{s}}=1,773$

Maka tip speed ratio rata-rata sebesar 1,860.

\section{Lebar sudu (Chord)}

Hugh Piggots memberikan formulasi untuk menentukan lebar sudu sebagai fungsi jarak dari pusat rotasi dengan memakai pendekatan Betz, maka diperoleh:

$$
\begin{aligned}
C & =\frac{16 \times \pi \times 0,375\left(\frac{0,375}{0,1875}\right)}{9 \times 1,860^{2} \times 8} \\
& =0,151 \mathrm{~m}=151 \mathrm{~mm}
\end{aligned}
$$




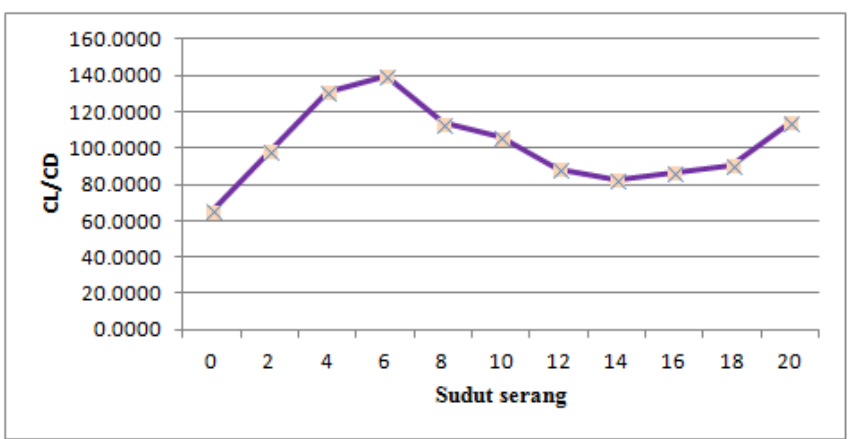

Gambar 2. Grafik hubungan antara $\mathrm{C}_{\mathrm{L}} / \mathrm{C}_{\mathrm{D}}$ dengan sudut serang $(\alpha)$

a. Berdasarkan gambar 2 terlihat bahwa $C_{\mathrm{L}} / \mathrm{C}_{\mathrm{D}}$ tertinggi terdapat pada sudut serang $6^{\circ}$ dengan nilai $\mathrm{C}_{\mathrm{L}}$ adalah $1,05, C_{D}$ adalah 0,0075 dan $C_{L} / C_{D}$ sebesar 140 . Sehingga dipillih besar sudut serang $(\alpha)$ dalam perancangan turbin angin jenis helical ini adalah $6^{\circ}$.

b. Sudut Pitch $(\beta)$

$$
\begin{aligned}
\beta & =\arctan \left(\frac{2 \times 0,375}{3 \times 0,1875 \times 1,860}\right)-6 \\
& =\arctan \left(\frac{1,5}{1,04625}\right)-6 \\
& =29,6^{\circ} \approx 30^{\circ}
\end{aligned}
$$

Karena sudut $\beta$ tegak lurus terhadap chord line, maka sudut $\beta$ adalah $90^{\circ}-30^{\circ}=60^{\circ}$. Sehingga pemasangan sudut pitch positif pada sudut $60^{\circ}$.

c. Solidity $(\sigma)$

$$
\begin{aligned}
\sigma & =\frac{C \cdot B}{2 \pi r} \\
& =\frac{0,151 \times 8}{2 \times \pi \times 0,1875}=0,514
\end{aligned}
$$

Ada beberapa distribusi gaya yang terjadi pada sudu turbin, yakni:

a. Besarnya gaya drag

$$
\begin{aligned}
F_{D} & =\frac{1}{2} C_{D} \rho V^{2} A \\
& =\frac{1}{2} \times 0,0075 \times 1,2 \times 2,2^{2} \times 0,90 \\
& =0,0196 \mathrm{~N}
\end{aligned}
$$

b. Besarnya gaya lift

$$
\begin{aligned}
F_{L} & =\frac{1}{2} C_{L} \rho V^{2} A \\
& =\frac{1}{2} \times 1,05 \times 1,2 \times 2,2^{2} \times 0,90 \\
& =2,7486 \mathrm{~N}
\end{aligned}
$$


c. Besarnya nilai resultan kecepatan angin

$$
\begin{aligned}
w_{r} & =V \sqrt{1+\left(\frac{r}{R} \lambda\right)^{2}} \\
& =2,2 \sqrt{1+\left(\frac{0,1875}{0,375} \times 1,860\right)^{2}} \\
& =3,00 \mathrm{~m} / \mathrm{s}
\end{aligned}
$$

d. Sudut Apparent Wind

$$
\begin{aligned}
\varphi & =\arctan \frac{R}{r \lambda} \\
& =\arctan \frac{0,375}{0,1875 \times 1,860}=47,08^{\circ}
\end{aligned}
$$

e. Besarnya gaya tangensial

$$
\begin{aligned}
F_{t} & =F_{L} \cos \varphi+F_{D} \sin \varphi \\
& =2,7486 \cos 47,08+0,0196 \sin 47,08 \\
& =1,8862 \mathrm{~N}
\end{aligned}
$$

f. Besarnya gaya aksial

$$
\begin{aligned}
F_{a} & =F_{L} \sin \varphi-F_{D} \cos \varphi \\
& =2,7486 \sin 47,08-0,0196 \cos 47,08 \\
& =1,9993 \mathrm{~N}
\end{aligned}
$$

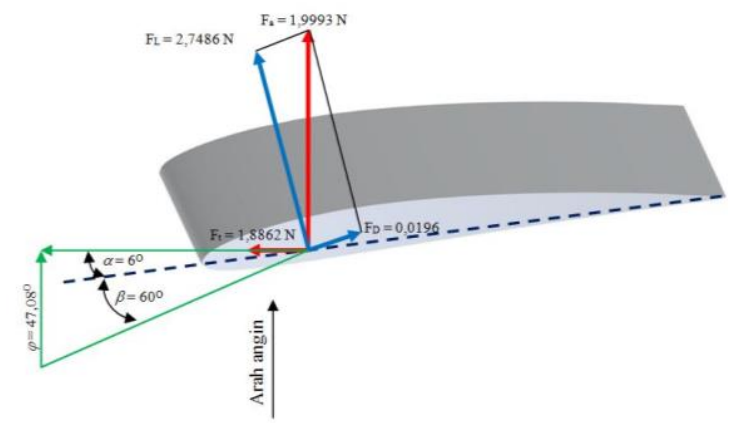

Gambar 3. Besar gaya-gaya yang terjadi pada sudu

Pada kondisi seperti ini, sudu dapat berputar dengan baik karena berdasarkan perhitungan yang telah dilakukan, terlihat bahwa hasilnya sesuai seperti yang diharapkan dimana gaya lift lebih besar dari pada gaya drag. Begitu pula dengan gaya aksial yang lebih besar dari pada gaya tangensial [7].

Besar daya teoritis yang dihasilkan dapat dilihat pada tabel 3 .

\section{Tabel 3}

Hasil Analisis Besar Daya Yang Dihasilkan

\begin{tabular}{|l|c|c|c|}
\hline \multicolumn{1}{|c|}{ Kondisi } & $\begin{array}{c}\mathbf{P}_{\mathbf{m}} \\
(\mathbf{W h})\end{array}$ & $\begin{array}{c}\mathbf{P}_{\mathbf{a}} \\
\mathbf{( W h )}\end{array}$ & $\begin{array}{c}\mathbf{P}_{\mathbf{t}} \\
\mathbf{( W h})\end{array}$ \\
\hline Kondisi 1 & 91,661 & 34,55 & 17,28 \\
\hline Kondisi 2 & 153,458 & 34,55 & 17,28 \\
\hline Kondisi 3 & 146,467 & 34,55 & 17,28 \\
\hline Kondisi 4 & 122,559 & 34,55 & 17,28 \\
\hline Total daya selama sehari & $\mathbf{5 1 4 , 1 5 4}$ & $\mathbf{1 3 8 , 2 1}$ & $\mathbf{6 9 , 1 1}$ \\
\hline
\end{tabular}




\section{Perhitungan dan Analisis Energi}

Beban yang digunakan merupakan lampu hemat energi dengan spesifikasi LED 55Watt 24 Volt DC. Sehingga untuk total energi listrik yang dibutuhkan untuk menerangi 2 buah lampu jalan selama 12 jam adalah:

Beban pemakaian $\left(\mathrm{P}_{\text {beban }}\right)$ :

$110 \mathrm{~W}$ x 12 hour $=1.320 \mathrm{Wh}$

Rugi-rugi sistem dianggap sebesar $15 \%$, sehingga total energi sistem sebesar:

$$
\begin{aligned}
\mathrm{E} & =\mathrm{P}+\text { rugi sistem } \\
& =1.320 \mathrm{Wh}+(1.320 \times 0,15) \\
& =1.518 \mathrm{Wh}
\end{aligned}
$$

Total arus yang mengalir pada beban sebesar:

$$
I=\frac{E}{V}=\frac{1.518 \mathrm{Wh}}{24 \mathrm{~V}}=63,25 \mathrm{Ah}
$$

Sehingga aki yang digunakan adalah aki kering yang tersedia di pasaran jenis VRLA Gel $24 \mathrm{~V}$ dengan kapasitas $70 \mathrm{Ah}$.

Daya listrik yang dibangkitkan dapat dihitung dengan menggunakan persamaan:

$$
\begin{aligned}
& \mathrm{P}=\mathrm{V} \times \mathrm{I} \times \eta_{\text {generator }} \\
& \mathrm{P}=28 \times 2,6 \times 0.95=69,16 \mathrm{~W}
\end{aligned}
$$

Turbin angin jenis helical ini beroperasi selama 24 jam, maka energi yang dihasilkan untuk masingmasing turbin adalah:

Daya listrik $=24$ hour $\times 69,16 \mathrm{~W}$

$$
=1.659,84 \mathrm{Wh}
$$

sedangkan untuk total arus yang dihasilkan oleh generator permanen magnet ini yakni:

Arus $\quad=24$ hour $\times 2,6 \mathrm{~A}$

$$
=62,4 \mathrm{Ah}
$$

Karena turbin helical yang digunakan sebanyak 2 unit, sehingga total energi yang dihasilkan yaitu:

Total daya listrik: $1.659,84 \mathrm{Wh} \times 2=3.319,69 \mathrm{Wh}$

Total arus listrik: $62,4 \mathrm{Ah}$ x $2=124,8 \mathrm{Ah}$

Total daya listrik yang dihasilkan oleh dua unit turbin angin jenis helical sebesar 3.319,69 Wh sehingga dapat memenuhi kebutuhan energi listrik untuk menerangi 2 buah lampu jalan selama 12 jam.

\section{Hasil Simulasi}

Perancangan turbin angin jenis helical dibuat dengan menggunakan software Pro- Engineering dengan skala 1:10 dan kemudian dilakukan simulasi putaran pada turbin angin helical dalam kondisi steady state dengan menggunakan software Computational Fluid Dynamics. Data yang di input berupa kecepatan angin sebesar 2,2 $\mathrm{m} / \mathrm{s}$ dan tekanan sebesar $1 \mathrm{~atm}$. 


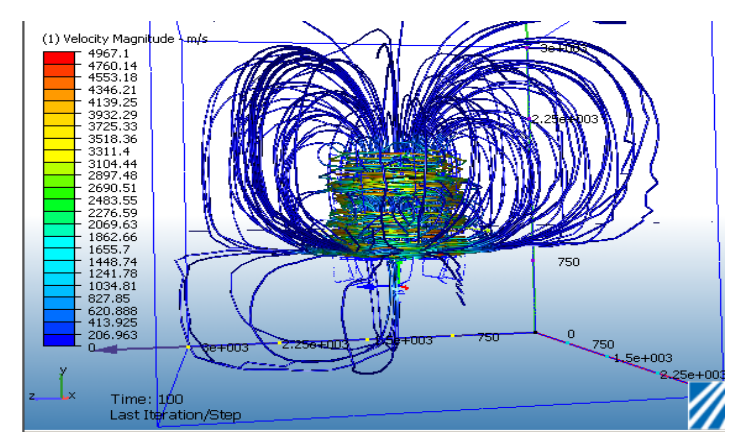

Gambar 4. Hasil analisis turbin angin helical (tampak samping)

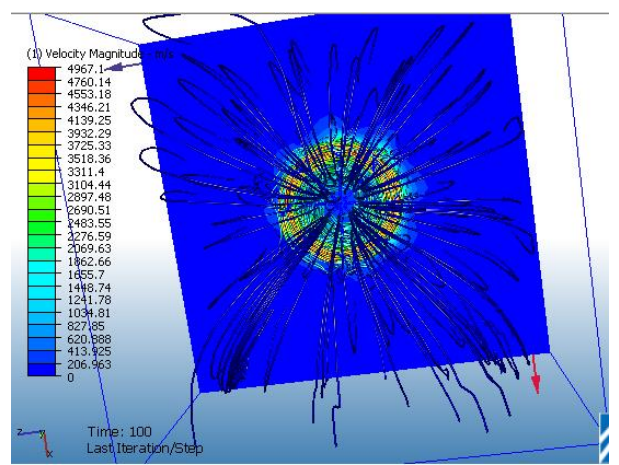

Gambar 5. Hasil analisis turbin angin helical (tampak atas)

Hasil simulasi pada gambar 4 dan gambar 5 menunjukkan bahwa aliran udara bersirkulasi di sekitar permukaan sudu turbin dengan kecepatan yang tinggi. Aliran udara yang ditangkap oleh satu profil sudu akan diteruskan ke sudu berikutnya. Sehingga aliran udara yang kecil pun dapat ditangkap oleh turbin angin dan didistribusikan secara maksimal.

\section{KESIMPULAN}

Berdasarkan analisis perhitungan dan simulasi, dapat disimpulkan:

1. Analisis konsep desain diperoleh jenis turbin yang paling baik adalah varian 1 sebagai konsep rancangan turbin angin jenis helical untuk sistem pembangkit listrik dengan lebar sudu $151 \mathrm{~mm}$ dan tinggi sudu $1.000 \mathrm{~mm}$

2. Hasil studi lapangan diperoleh jumlah kendaraan yang melintas selama 4 jam sebanyak 3.977 buah dan data kecepatan angin rata-rata sebesar $2,2 \mathrm{~m} / \mathrm{s}$ serta kecepatan angin tertinggi sebesar $4,81 \mathrm{~m} / \mathrm{s}$. Hal ini menunjukkan bahwa hembusan angin yang diperoleh saat kendaraan melintas berpotensi sebagai sumber energi untuk membangkitkan listrik pada turbin angin. Sehingga jenis turbin yang cocok untuk digunakan adalah Helical VAWT.

3. Hasil dari identifikasi kebutuhan energi listrik untuk penerangan jalan adalah sebesar $1.518 \mathrm{Wh}$ untuk menerangi 2 buah lampu jalan LED selama 12 jam. Hasil analisis besarnya daya listrik yang dihasilkan oleh 2 unit turbin angin jenis helical sebesar 3.319,69 Wh. Hasil perhitungan tersebut menunjukkan bahwa turbin angin jenis helical ini dapat memenuhi kebutuhan listrik lampu jalan. 
17 Nur Rahmah H. Anwar. Perancangan Turbin Angin Jenis Helical untuk Sistem Pembangkit Listrik

\section{DAFTAR PUSTAKA}

[1] Djati Widodo, Imam., Perencanaan dan Pengembangan Produk, UII Press Indonesia, Yogyakarta, 2003.

[2] Dutta, Animesh, Basic of Wind Technology, Asian Institute of Technology Thailand, 6 Juli 2006.

[3] John, Mc Cosker., Design and Optimization of a Small Wind Turbine, Rensselaer Polytechnic Institute Hartford, 2012.

[4] Ingram, Grant., Wind Turbine Blade Analysis Using the Blade Element Momentum Methode, 18 Oktober 2011.

[5] Mittal, Neeraj, Investigation of Performance Characteristic of a Novel VAWT, Thesis UK Depertment of Mechanical Engineering University of Strathclyde, 2001.

[6] Abedi, Hamidreza., Aerodinamic Loads On Rotor Blades, Chalmers University of Technology, 2011.

[7] John, Mc Cosker., Design and Optimization of a Small Wind Turbine, Rensselaer Polytechnic Institute Hartford, 2012. 